\title{
Age-Related Increases in the Shoulder Strength of High School Wrestlers
}

\author{
Terry J. Housh, Rommie J. Hughes, Glen O. Johnson, \\ Dona J. Housh, Loree L. Wagner, Joe P. Weir, \\ and Sharon A. Evans
}

\begin{abstract}
The purpose of this investigation was to examine age-related differences in absolute and relative isokinetic shoulder strength of high school wrestlers. A total of 122 high school wrestlers $(M$ age $=16.31 \pm 1.18 \mathrm{yrs}$ ) volunteered to be measured for arm flexion and extension strength at the shoulder joint using a Cybex II dynamometer at 30,180 , and $300^{\circ} \cdot \mathrm{s}^{-1}$. The sample was divided into four age groups: $13.75-15.00(n=22), 15.08-16.00(n=27), 16.08-17.00$ $(n=34)$, and $17.08-18.83$ years $(n=39)$. The results of this study indicated significant increases in absolute and relative arm flexion and extension strength across age when covaried for BW and FFW. In addition, comparisons with previously published data indicated differences between muscle groups in the pattern of strength gains that were dependent upon the speed of muscular contraction and may have been influenced by fiber type distribution characteristics.
\end{abstract}

Many factors such as strength, body composition, anaerobic capabilities, and strategic knowledge contribute to the improvement in wrestling performance which normally occurs throughout the high school years $(4,9,10,13)$. However, few studies have examined the development of these traits in wrestlers during adolescence. This is especially true with regard to strength for movements other than flexion and extension of the forearm and leg. For example, there have been no studies describing the strength characteristics of high school wrestlers at the shoulder joint, even though the demands of the sport require a substantial amount of strength in these muscle groups and changes in shoulder strength are likely to influence wrestling performance. In addition, information regarding the development of shoulder strength in high school wrestlers can be compared to existing data (10) to examine the differences in the patterns of strength gains between muscle groups of the upper versus lower body as well as between the muscles associated with movements at the elbow versus shoulder joints. Therefore the purpose of this investigation was to examine age related differences in absolute and relative isokinetic shoulder strength of high school wrestlers.

The authors are with the Center for Youth Fitness and Sports Research at the University of Nebraska-Lincoln, Lincoln, NE 68588-0138. 


\section{Materials and Methods}

A total of 122 high school wrestlers $(M$ age $=16.31 \pm 1.18 \mathrm{yrs})$ volunteered as subjects for this study. They were stratified into four groups corresponding approximately to the ages of wrestlers during their freshman, sophomore, junior, and senior years in high school: Group $1(\mathrm{G} 1)=13.75-15.00 \mathrm{yrs}(n=22)$, Group $2(\mathrm{G} 2)=15.08-16.00$ yrs $(n=27)$, Group $3(\mathrm{G} 3)=16.08-17.00$ yrs $(n=34)$, and Group $4(\mathrm{G} 4)=17.08-18.83$ yrs $(n=39)$. All measurements were taken during the preseason (1-2 weeks prior to the competitive season) and informed consent was obtained from each wrestler and his parents prior to inclusion in the study.

Body composition was assessed from underwater weighing using the procedures described by Thorland et al. (21) with corrections for residual lung volumes using oxygen dilution (24). Relative fat (RF) was calculated from body density using both the conversion constants of Brozek et al. (3) and the age-specific conversion constants of Lohman (16) with fat-free weight (FFW) derived mathematically. Body weight (BW) and height (HT) were obtained using a physician's scale and a wall scale with Broca plane, respectively.

Isokinetic flexion and extension strength at the shoulder joint of the dominant arm (based on throwing preference) were measured using a Cybex II dynamometer at 30,180 , and $300^{\circ} \cdot \mathrm{s}^{-1}$. All subjects were positioned and stabilized using the procedures recommended by the manufacturer (11). Three to four submaximal warm-up trials were followed by three consecutive maximal efforts, with the highest peak torque value selected as the representative score. Dampening on the Cybex II was set at 2 .

One-way ANOVA with Tukey post hoc comparisons were used to locate significant differences $(p<0.05)$ between groups for HT, BW, RF, and FFW as well as absolute flexion and extension strength. One-way ANCOVA were used to locate significant differences between groups for flexion and extension strength covaried independently for BW and FFW.

\section{Results}

Table 1 presents the descriptive characteristics of the subjects. The age, HT, RF, and BW of the subjects in the present study were similar to samples of adolescent wrestlers previously described $(9,10,15,18,19,21,23)$.

There were significant $(r=0.18, p<0.05)$ zero-order correlations among all variables except RF, which was not associated with HT, BW, or any of the strength measures. The highest correlation was found between BW and FFW $(r=0.93)$ and the measures of muscular strength were significantly intercorrelated $(r=0.75$ to 0.92$)$. All first-order partial correlations among the strength measures (controlling for BW and FFW) were also significant but were generally reduced from the zero-order values and ranged from $r=0.46$ to 0.87 . In addition, there were significant ( $r=0.37$ to 0.50 ) first-order partial correlations (controlling for BW and FFW) between age and all of the strength measures.

Table 2 includes the results of the one-way ANOVA and ANCOVA analyses across age for arm flexion and extension strength at 30,180 , and $300^{\circ} \bullet \mathrm{s}^{-1}$. In all cases there were significant $(p<0.05)$ increases across age for absolute and relative strength (covaried for BW and FFW), with G4 and G3 always stronger than G1. 


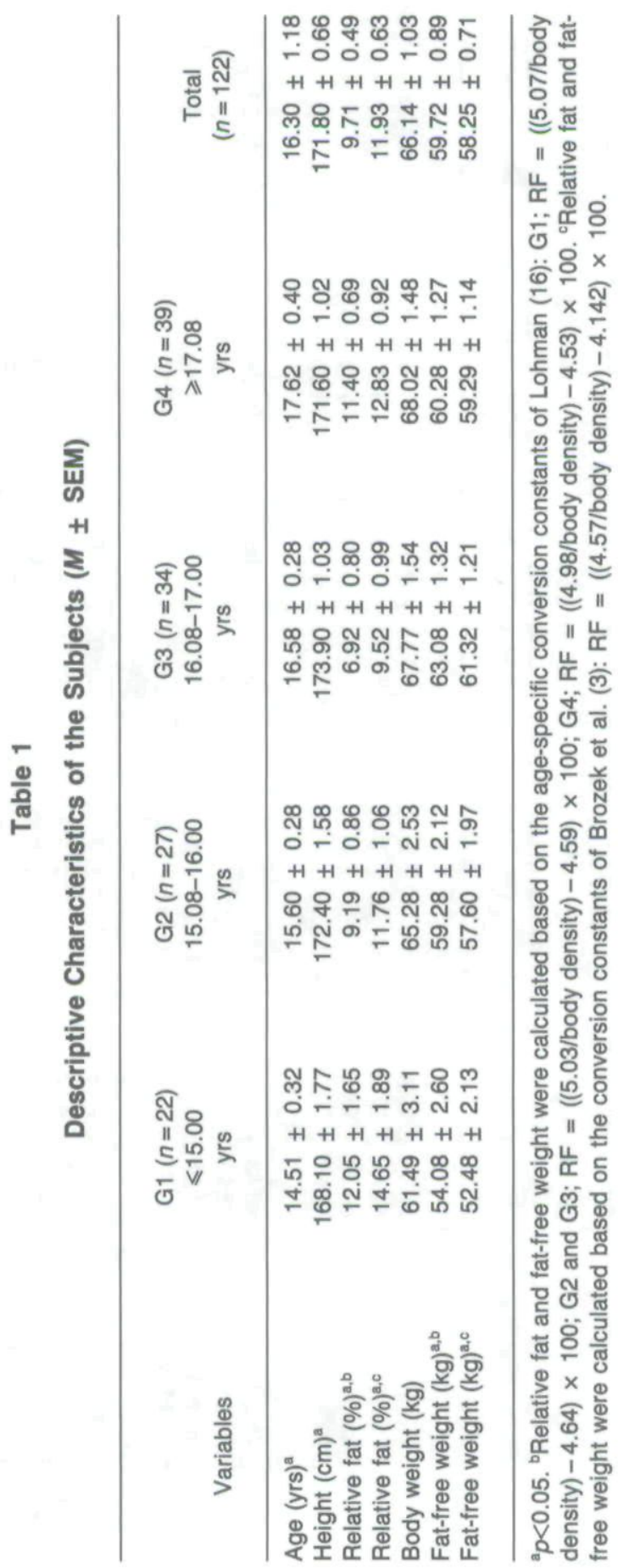




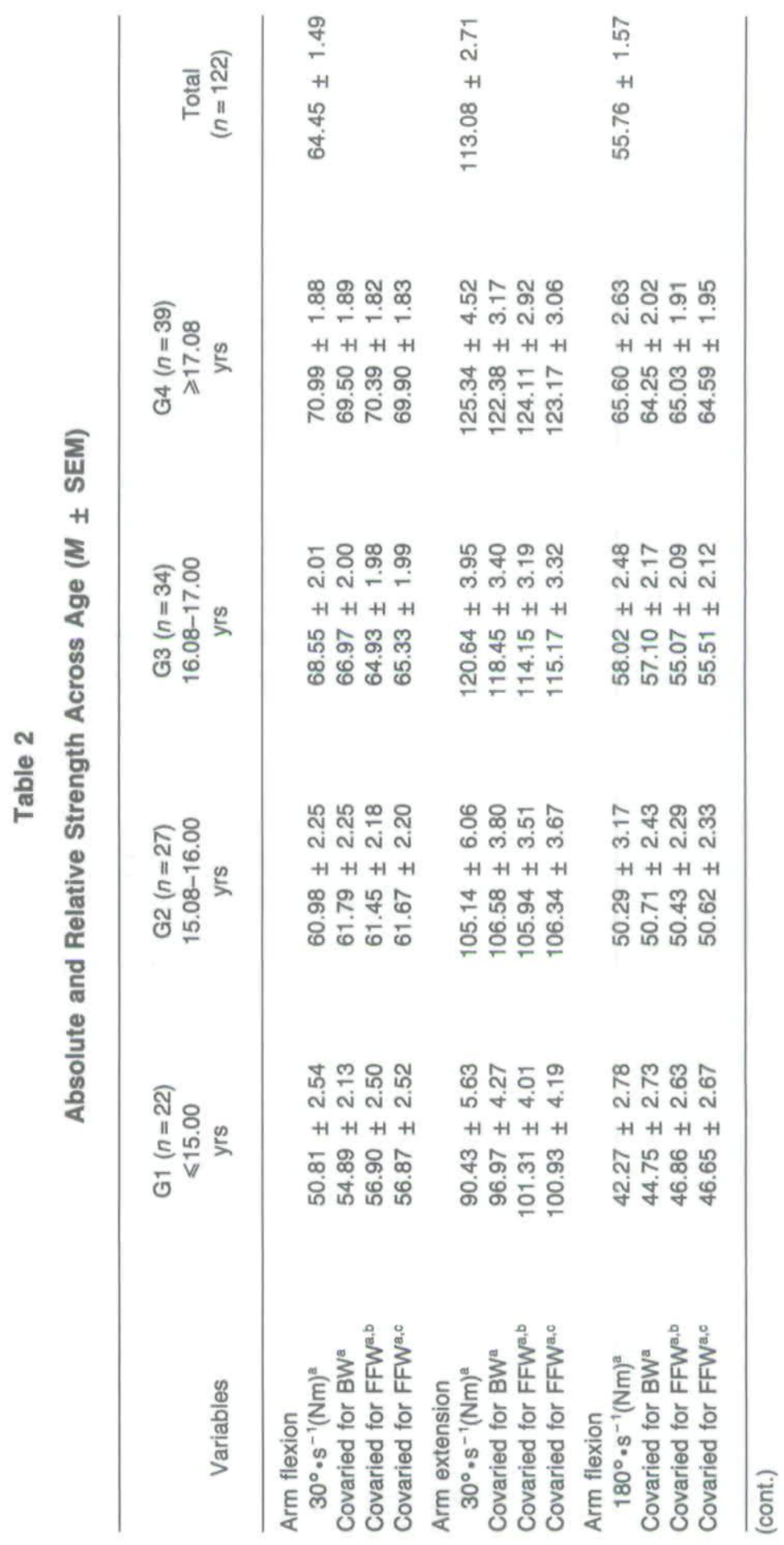




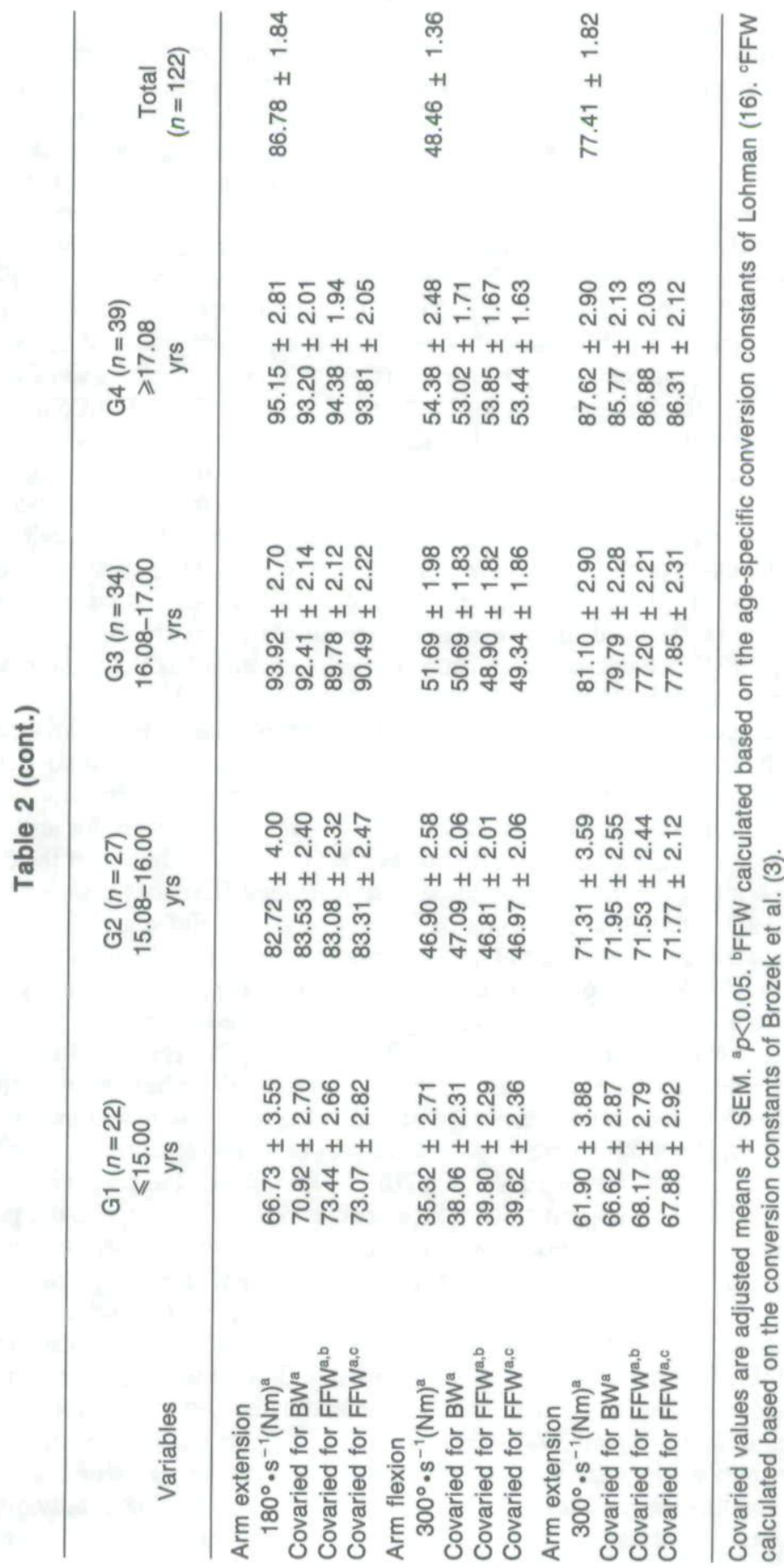




\section{Discussion}

Few studies have provided normative data with regard to isokinetic flexion and extension strength at the shoulder joint $(1,2,5,12)$. Furthermore, only one of these studies (1) reported absolute peak torque values while the others presented correlations or ratio comparisons for agonist versus antagonist muscle groups $(2,12)$, dominant versus nondominant arms $(5,12)$, athletes versus nonathletes (5), or strength values relative to BW or FFW $(2,12)$. Alderink and Kuck (1) found that the peak torque values for arm flexion and extension at $300^{\circ} \cdot \mathrm{s}^{-1}$ for a sample that included both high school and college-age baseball pitchers were 38.24 and $78.51 \mathrm{Nm}$, respectively. These values represented 78.9 and $101.4 \%$ of the strength for the high school wrestlers in the present study. When strength was expressed relative to BW, however, the high school wrestlers were substantially stronger than the pitchers for both arm flexion $(0.73 \mathrm{vs} .0 .48 \mathrm{Nm} / \mathrm{kg})$ and extension $(1.17$ vs. $0.99 \mathrm{Nm} / \mathrm{kg}$ ). In addition, previous investigations $(1,12)$ have reported arm flexion/extension strength ratios ranging from 0.48 to 0.80 . The corresponding value for the high school wrestlers in the present study was 0.63 , which indicated some disagreement among these investigations. Although the reason for the discrepancies is unclear, Alderink and Kuck (1) have suggested that athletes such as pitchers may develop exceptionally strong extensors. This appears not to be the case, however, given the similarity in absolute peak torque values and $18 \%$ greater arm extension strength per unit of BW for the wrestlers in the present study compared to the baseball pitchers.

As indicated in Table 2, adjustment of the strength values for FFW calculated using either the conversion constants of Brozek et al. (3) or Lohman (16) had little effect on the group differences found in the present study. Post hoc analyses indicated that the only differences between the two approaches were for arm flexion and extension at $30^{\circ} \cdot \mathrm{s}^{-1}$ and arm flexion at $300^{\circ} \cdot \mathrm{s}^{-1}$, where the use of the conversion constants of Lohman (16) resulted in significant differences between G4 and G3 while the use of the constants of Brozek et al. (3) did not.

Typically, increases in muscular strength across age coincide with changes in BW and FFW. However, recent investigations have described an age effect for flexion and extension strength at the elbow and knee joints that could not be accounted for by changes in BW or FFW $(10,20)$. The results of the present investigation established that the age effect also occurred for flexion and extension at the shoulder joint. It has been suggested that the mechanism that underlies the age effect involves either neuromuscular factors or an increase in the contribution of muscle mass per unit of FFW $(10,20)$. The results of the present investigation, however, also suggested differences between muscle groups in the patterns of strength gains that were dependent upon the speed of muscular contraction. For example, the increase in strength covaried for FFW across age for forearm and leg measurements described previously by Housh et al. (10) were found only at 30 (forearm flexion and leg extension) and $180^{\circ} \cdot \mathrm{s}^{-1}$ (forearm flexion).

At the shoulder joint in the present investigation, however, strength relative to FFW increased with age for both flexion and extension at all three speeds of contraction $\left(30,180\right.$, and $\left.300^{\circ} \cdot \mathrm{s}^{-1}\right)$. These data support the hypothesis that fiber type distribution characteristics may influence the expression of strength across age (20). Given that the muscles within an individual can have substantially different percentages of fast and slow twitch fibers $(7,14,17)$ and that force capabilities 
are in part dependent upon the twitch characteristics of the muscle fiber $(6,8$, 22 ), the age effect may be evident at different speeds of contraction depending upon the fiber type distribution characteristics of the muscles involved. Further research is needed to determine whether changes in muscular strength across adolescence are influenced by an interaction between developmental processes and fiber type characteristics.

In summary, this investigation provided unique data regarding the shoulder strength characteristics of high school wrestlers and confirmed the occurrence of an age effect in the muscle groups associated with flexion and extension at the shoulder joint. The results of the present study, when considered in conjunction with previously reported data involving flexion and extension strength at the knee and elbow joints (10), also suggested differences between muscle groups in the patterns of strength gains across adolescence that were dependent upon the speed of muscular contraction and may have been influenced by fiber type distribution characteristics.

\section{References}

1. Alderink, G.J., and D.J. Kuck. Isokinetic shoulder strength of high school and collegeaged pitchers. J. Ortho. Sports Phys. Ther. 7:163-172, 1986.

2. Beam, W.C., R.L. Bartels, and R.W. Ward. The relationship of isokinetic torque to body weight and to lean body weight in athletes. Med. Sci. Sports Exer. (Abstract) $14: 178,1982$.

3. Brozek, J., F. Grande, J.T. Anderson, and A. Keys. Densiometric analysis of body composition: Revision of some quantitative assumptions. Ann. NY Acad. Sci. 10:113-140, 1963.

4. Cisar, C.J., G.O. Johnson, A.C. Fry, T.J. Housh, R.A. Hughes, and A.J. Ryan. Preseason body composition, build and strength as predictors of high school wrestling success. J. Appl. Sports Sci. Res. 1:66-70, 1987.

5. Cook, E.E., V.L. Gray, E. Savinar-Nogul, and J. Medeiros. Shoulder antagonist strength ratios: A comparison between college-level baseball pitchers and nonpitchers. J. Ortho. Sports Phys. Ther. 8:451-461, 1987.

6. Coyle, E.F., D.L. Costill, and G.R. Lesmes. Leg extension power and muscle fiber composition. Med. Sci. Sports 11:12-15, 1979.

7. Elder, G.C.B., K. Bradbury, and R. Roberts. Variability of fiber type distributions within human muscles. J. Appl. Physiol.: Respirat. Environ. Exercise Physiol. 53:1473-1480, 1982.

8. Gregor, R.J., V.R. Edgerton, J.J. Perrine, D.S. Campion, and C. DeBus. Torquevelocity relationships and muscle fiber composition in elite female athletes. J. Appl. Physiol. 47:388-392, 1979.

9. Housh, T.J., G.O. Johnson, R.A. Hughes, C.J. Cisar, and W.G. Thorland. Yearly changes in the body composition and muscular strength of high school wrestlers. Res. Q. Exer. Sport 59:240-243, 1988.

10. Housh, T.J., G.O. Johnson, R.A. Hughes, D.J. Housh, R.J. Hughes, A.S. Fry, K.B. Kenney, and C.J. Cisar. Isokinetic strength and body composition of high school wrestlers across age. Med. Sci. Sports Exer. 21:105-109, 1989.

11. Isolated Joint Testing and Exercise: A Handbook for Using the Cybex II and U.B.X.T. Ronkonkoma, NY: Cybex, Division of Lumex, 1981, pp. 37-38. 
12. Ivey, F.M., J.H. Calhoun, K. Rusche, and J. Bierschenk. Normal values for isokinetic testing of shoulder strength. Med. Sci. Sports Exer. (Abstract) 16:127, 1984.

13. Johnson, G.O., and C.J. Cisar. Basic conditioning principles for high school wrestlers. Phys. Sportsmed. 15:153-159, 1987.

14. Johnson, M.A., J. Polgar, D. Weightman, and D. Appleton. Data on distribution of fiber types in thirty-six human muscles. An autopsy study. J. Neurol. Sci. 18:111-129, 1973.

15. Katch, F.I., and E.D. Michael. Body composition of high school wrestlers according to age and wrestling weight category. Med. Sci. Sports 3:190-194, 1971.

16. Lohman, T.G. Applicability of body composition techniques and constants for children and youths. In: Exercise and Sports Sciences Reviews, K.B. Pandolf (Ed.). New York: Macmillan, 1987, pp. 325-357.

17. Monster, A.W., H.C. Chan, and D. O'Connor. Activity patterns of human skeletal muscles: Relation to muscle fiber type composition. Science 200:314-317, 1978.

18. Oppliger, R.A., and C.M. Tipton. Iowa wrestling study: Cross-validation of the Tcheng-Tipton minimal weight prediction formulas for high school wrestlers. Med. Sci. Sports Exer. 20:310-316, 1988.

19. Tcheng, T., and C.M. Tipton. Iowa wrestling study: Anthropometric measurements and the prediction of a "minimal" body weight for high school wrestlers. Med. Sci. Sports 5:1-10, 1973.

20. Thorland, W.G., G.O. Johnson, C.J. Cisar, T.J. Housh, and G.D. Tharp. Strength and anaerobic responses of elite young female sprint and distance runners. Med. Sci. Sports Exer. 19:56-61, 1987.

21. Thorland, W.G., G.O. Johnson, T.G. Fagot, G.D. Tharp, and R.W. Hammer. Body composition and somatotype characteristics of junior Olympic athletes. Med. Sci. Sports Exer. 13:332-338, 1981.

22. Thorstensson, A., L. Larsson, P. Tesch, and J. Karlsson. Muscle strength and fiber composition in athletes and sedentary men. Med. Sci. Sports 9:26-30, 1977.

23. Williford, H.N., J.F. Smith, E.R. Mansfield, M.D. Conerly, and P.A. Bishop. Validation of body composition models for high school wrestlers. Med. Sci. Sports Exer. 18:216-224, 1986.

24. Wilmore, J.H. A simple method for determination of residual lung volumes. J. Appl. Physiol. 27:96-100, 1969. 
Copyright of Pediatric Exercise Science is the property of Human Kinetics Publishers. Inc. and its content may not be copied or emailed to multiple sites or posted to a listserv without the copyright holder's express written permission. However, users may print, download, or email articles for individual use. 